\title{
Induction of apoptosis in HeLa cancer cells by an ultrasonic-mediated synthesis of curcumin-loaded chitosan-alginate-STPP nanoparticles
}

This article was published in the following Dove Press journal: International Journal of Nanomedicine

\author{
Fatemeh Ahmadi' \\ Maryam Ghasemi-Kasman ${ }^{2,3}$ \\ Shahram Ghasemi ${ }^{4}$ \\ Maryam Gholamitabar \\ Tabari $^{5}$ \\ Roghayeh Pourbagher ${ }^{2}$ \\ Sohrab Kazemi ${ }^{6}$ \\ Ali Alinejad-Mir ${ }^{7}$
}

'Student Research Committee, Babol University of Medical Sciences,

${ }^{2}$ Cellular and Molecular Biology

Research Center, ${ }^{3}$ Neuroscience

Research Center, Health Research

Institute, Babol University of Medical

Sciences, Babol, Iran; ${ }^{4}$ Faculty of

Chemistry, University of Mazandaran,

Babolsar, Iran; ${ }^{5}$ Infertility and Health

Reproductive Research Center, Health

Research Institute, ${ }^{6} \mathrm{Cancer}$ Research

Center, Health Research Institute,

Babol University of Medical Sciences,

Babol, Iran; ${ }^{7}$ Department of Chemical

Engineering, University of Mazandaran, Babolsar, Iran
Correspondence: Maryam GhasemiKasman

Health Research Institute, Babol University of Medical Sciences, PO Box 4|36747/76, Babol, Iran Tel/fax+98 II 32190557

Emailm.ghasemi@mubabol.ac.ir

\begin{abstract}
Natural herbal compounds have been widely introduced as an alternative therapeutic approach in cancer therapy. Despite potent anticancer activity of curcumin, its clinical application has been limited because of low water solubility and resulting poor bioavailability. In this study, we designed a novel ultrasonic-assisted method for the synthesis of curcumin-loaded chitosan-alginate-sodium tripolyphosphate nanoparticles (CS-ALG-STPP NPs). Furthermore, antitumor effect of curcumin-loaded NPs was evaluated in vitro. Field emission scanning electron microscopy (FE-SEM) and atomic force microscopy (AFM) were used to characterize the properties of NPs. Antitumor activity of curcumin-loaded NPs was assessed by using MTT and quantitative real-time polymerase chain reaction (qRT-PCR). FE-SEM and AFM data revealed the spherical morphology, and the average size of NPs was $<50 \mathrm{~nm}$. In vitro cytotoxicity assay suggested that curcumin-loaded CS-ALG-STPP NPs displayed significant antitumor activity compared with the free curcumin. Gene expression level analyses showed that curcumin NPs significantly increased the apoptotic gene expression. Collectively, our results suggest that curcumin-loaded NPs significantly suppressed proliferation and promoted the induction of apoptosis in human cervical epithelioid carcinoma cancer cells, which might be regarded as an effective alternative strategy for cancer therapy.
\end{abstract}

Keywords: cancer, curcumin, biodegradable nanoparticles, antitumor activity, apoptosis induction

\section{Introduction}

Curcumin is a yellow polyphenol derived from the turmeric rhizome (Curcuma longa). ${ }^{1}$ A growing number of studies have indicated that curcumin has several beneficial properties such as antitumor, ${ }^{2,3}$ antioxidant, ${ }^{4}$ anti-amyloid, ${ }^{5}$ anti-inflammatory, ${ }^{6}$ antimicrobial, ${ }^{7}$ and wound healing effects. ${ }^{8}$ Previous studies suggested that curcumin alone or in combination with other anticancer drugs possesses potent antitumor activity on different tumor cell lines including hepatic, ${ }^{9}$ prostatic, ${ }^{10}$ ovarian, ${ }^{11}$ breast, ${ }^{12}$ pancreatic, ${ }^{13}$ and gastric carcinomas. ${ }^{14}$ Furthermore, it has been reported that curcumin has significant effects on carcinogenesis signaling pathways through angiogenesis inhibition, ${ }^{13}$ cell death activation, ${ }^{15}$ and cell cycle arrest induction. ${ }^{16}$ Despite promising antitumor activity of curcumin, its clinical application has been hampered due to rapid systemic elimination and low aqueous solubility that limits the bioavailability of this bioactive compound. ${ }^{17,18}$ To overcome these limitations, different approaches have been used to improve curcumin solubility including the encapsulation of curcumin in liposome, ${ }^{19}$ dendrimers ${ }^{20}$ polymeric nanoparticles (NPs) ${ }^{21}$ nanogel, ${ }^{22}$ cyclodextrin, ${ }^{23}$ and biodegradable microsphere. ${ }^{24}$ Because of the hydrophobic nature of curcumin, its 
encapsulation by natural biocompatible and biodegradable polymers has been introduced as a promising strategy for cancer therapy. Alginate (ALG) and chitosan (CS) are two natural biopolymers that have numerous pharmaceutical and biomedical applications. ${ }^{25}$ ALG is a water-soluble linear polysaccharide extracted from brown seaweed, and ALG NPs can be obtained by adding sodium tripolyphosphate (STPP) and polycationic solution, resulting in the formation of polyelectrolyte complex. ${ }^{26}$ Because of low immunogenicity and nontoxic properties of CS, it has been selected as an alternative cationic polymer. ${ }^{27}$ Ample evidence has shown that curcumin NPs can be prepared by using $\mathrm{CS}^{28,29}$ or ALG. ${ }^{30,31}$ In addition, a previous study suggested that curcumin can be encapsulated with ALG, CS, and pluronic composite, which could significantly enhance the anticancer activity of curcumin. ${ }^{32}$ Furthermore, curcumin has been incorporated into CS-ALG sponge to improve its wound healing property. ${ }^{33,34}$ More recently, curcumin NPs have been produced by using CS, ALG, TPP, and calcium chloride. ${ }^{35}$ Regarding the necessity of finding an alternative drug delivery system for cancer therapy, the present study describes a new approach for loading curcumin onto CS, ALG, and STPP NPs by an ultrasonic-assisted method. Then, the effects of curcumin-loaded NPs on proliferation and apoptosis were investigated in human cervical epithelioid carcinoma (HeLa) cancer cell lines.

\section{Materials and methods Chemicals}

Curcumin powder was purchased from Merck Company, Darmstadt, Germany. CS and ALG were obtained from Sigma-Aldrich (St Louis, MO, USA). STPP was prepared from Daejung, Sasang-gu, Busan, South Korea. Culture medium materials and MTT were purchased from ATOCEL (Graz, Austria) and Alfa Aesar (Ward Hill, MA, USA), respectively.

\section{Preparation of curcumin-loaded CS-ALG- STPP NPs}

CS-ALG-STPP NPs were prepared according to Caetano et al's report, with some modifications. ${ }^{36}$ Ten milligram of CS was dissolved in 1\% acetic acid to reach a final concentration of $1 \mathrm{mg} / \mathrm{mL}$ by magnetic stirring, and its $\mathrm{pH}$ was adjusted to 4.9. CS solution was stirred by ultrasonic irradiation (Bandelin, Berlin, Germany) for 1 hour. Curcumin powder was then dissolved in a small quantity of ethanol, and $1 \mathrm{~mL}$ of its solution ( $1 \mathrm{mg} / \mathrm{mL}$ in ethanol) was added in CS solution with stirring; $5 \mathrm{mg}$ of ALG was dissolved in distilled water, and $\mathrm{pH}$ of the suspension was adjusted to 4.6 by $\mathrm{HCl}(0.5 \mathrm{M})$. ALG was added dropwise to this solution, followed by dropwise addition of STPP $(0.13 \% \mathrm{w} / \mathrm{v}$ in ultrapure deionized water) using an insulin syringe (flow rate: $1 \mathrm{~mL} / \mathrm{min}$ ) under high-speed stirring for 120 minutes. The resulting mixture was collected and washed with $10 \%$ ethanol and water by centrifugation at $14,000 \mathrm{rpm}$ for 30 minutes at $4^{\circ} \mathrm{C}$.

\section{NP characterization}

The surface morphology and size distribution of curcuminloaded ALG-CS-STPP NPs were characterized by field emission scanning electron microscopy (FE-SEM; Mira 3 XMU; TESCAN, Brno, Czech Republic), atomic force microscopy (AFM; Easyscan 2 Flex, Liestal, Switzerland), and Fourier transform infrared (FT-IR) spectroscopy. The FT-IR spectroscopy of curcumin, ALG-CS-STPP NPs, and curcumin-loaded NPs were obtained by using FT-IR spectrophotometer (Vector 22 FT-IR; Bruker Optik GmbH, Ettlingen, Germany).

\section{Encapsulation efficiency}

To determine the amount of curcumin entrapment, highperformance liquid chromatography (HPLC) analysis (Knauer; Smartline, Berlin, Germany) was performed. As we mentioned previously, at the final step of NP preparation, curcumin-CS-ALG-STPP solution was centrifuged, and the decanted solution was collected. After washing the mixture with ethanol, supernatant was collected, and the amount of remaining curcumin was evaluated. In addition, $1 \mathrm{mg}$ of air-dried NPs was dissolved in $1 \mathrm{~mL}$ of water, and curcumin loaded onto NPs has been extracted using acetonitrile. The HPLC column was C18 (Eurospher, Knauer; Smartline, Berlin, Germany), and the mobile phase was a mixture of acetonitrile and water in a ratio of 90:10 (v/v). The flow rate of the mobile phase was $1 \mathrm{~mL} / \mathrm{min}$, and the eluent was detected by ultraviolet (UV) detector at a wave length of $425 \mathrm{~nm}$.

Area under the peaks was measured by using EZChrom software, and then, the amount of curcumin was calculated using a standard curve. Curcumin loading efficiency was calculated using the following formula: ${ }^{37}$

$$
\begin{aligned}
& \text { Loading efficiency }(\%) \\
& =\frac{\text { Total amount of curcumin }- \text { Free curcumin }}{\text { Total amount of curcumin }} \times 100
\end{aligned}
$$

\section{In vitro release studies}

The in vitro release of curcumin from NPs was carried out according to a previous report. ${ }^{32}$ Briefly, $5 \mathrm{mg}$ of airdried curcumin-loaded NPs was dispersed in $32 \mathrm{~mL}$ PBS 
( $\mathrm{pH} 7.4$ ), and the resulting solution was divided and kept in 16 microfuge tubes (each $2 \mathrm{~mL}$ ). At time intervals of $0,1,2$, $3,4,5$, and 24 hours, the solution was centrifuged at 10,000 rpm for 10 minutes. The released curcumin was dissolved in $2 \mathrm{~mL}$ absolute ethanol, and the absorbance was measured using UV spectrophotometer (SQ4802; UNICO, Dayton, NJ, USA) at a wavelength of $425 \mathrm{~nm}$. The in vitro release profile was measured by using the following equation:

$$
\text { Release }(\%)=\frac{\mathrm{C}_{t}}{\mathrm{C}_{0}} \times 100
$$

where $\mathrm{C}_{\mathrm{t}}$ represents the concentration of released curcumin at the time $\mathrm{t}$, and $\mathrm{C}_{0}$ is the total amount of curcumin loaded in CS-ALG-STPP NPs.

\section{Adsorption isotherm study}

Isotherm experiments were performed according to a previous report by Cheng et al..$^{38}$ In brief, different concentrations of curcumin $(0.1,0.15,0.2,0.25$, and $0.3 \mathrm{mg} / \mathrm{mL})$ were mixed with CS-ALG-STPP NPs, and the resulting mixture was continuously shaken for 24 hours at $25^{\circ} \mathrm{C}$. The adsorption capacity of CS-ALG-STPP NPs for curcumin was calculated by using the following equation:

$$
\mathrm{q}_{\mathrm{e}}=\frac{\left(\mathrm{C}_{0}-\mathrm{C}_{\mathrm{e}}\right) \mathrm{V}}{\mathrm{m}}
$$

where $\mathrm{C}_{0}$ is considered as the initial concentration of curcumin $(\mathrm{mg} / \mathrm{mL})$, and $\mathrm{C}_{\mathrm{e}}$ is the curcumin concentration in equilibrium state; $\mathrm{V}$ and $\mathrm{m}$ are the total volume of the mixture $(\mathrm{mL})$ and the total mass of CS-ALG-STPP NPs, respectively; and $\mathrm{q}_{\mathrm{e}}$ and $\mathrm{C}_{\mathrm{e}}$ values (as dependent variables) were obtained through the experiments. In order to determine the curcumin adsorption onto CS-ALG-STPP NPs and the maximum uptake $\left(\mathrm{q}_{\max }\right)$, data were fitted to several isotherm equations including Langmuir, Freundlich, Temkin, Elovich, and Langmuir-Freundlich.

\section{Cell culture assays}

To evaluate the cellular uptake of curcumin, HeLa cancer cell line was purchased from Pasture Institute, Tehran, Iran. Cells were cultured in Roswell Park Memorial Institute medium supplemented with $10 \%$ fetal bovine serum and $1 \%$ penicillin/ streptomycin at $37^{\circ} \mathrm{C}$ in $\mathrm{CO}_{2}$ incubator. The cells were treated with $50 \mu \mathrm{g} / \mathrm{mL}$ free curcumin or curcumin-loaded NPs. After 24 hours, the treated cells were washed with PBS and then examined under an inverted fluorescence microscope
(Nikon Instruments, Melville, NY, USA). In order to assess the cytotoxic effects of curcumin-loaded NPs, human foreskin fibroblasts and HeLa cells with a density of $7 \times 10^{3}$ were seeded in 96-well plates and incubated with different concentrations of free and encapsulated curcumin for 48 hours. Then, MTT ( $5 \mathrm{mg} / \mathrm{mL}$ ) was added to each well, and the cells were incubated for 4 hours at $37^{\circ} \mathrm{C}$. For dissolving the blue formazan precipitate, dimethyl sulfoxide was added, and the absorbance was determined at $570 \mathrm{~nm}$ by an ELISA reader (BioTek, Winooski, VT, USA). The percentage of cell viability was obtained by using the following equation:

$$
\text { Cell viability }(\%)=\frac{\text { Absorbance of treated cells }}{\text { Absorbance of untreated cells }} \times 100
$$

All cell culture assessments were performed in triplicate.

\section{Nuclear staining}

Like MTT assay, cells from the HeLa cell line were cultured and incubated with blank NPs, curcumin, or curcumin-loaded NPs for 48 hours. Then, the cells were washed with PBS and fixed with cold 4\% paraformaldehyde for 20 minutes. After washing with PBS, for enhancing the permeability, $0.2 \%$ Triton X-100 was added for 20 minutes; at the final stage, nuclear staining was performed using DAPI $(1 \mu \mathrm{g} / \mathrm{mL}$; Santa Cruz Biotechnology Inc., Santa Cruz, CA, USA) for 25 minutes, and the cells were observed under a fluorescence microscope (Nikon).

\section{Quantitative real-time polymerase chain reaction ( $q R T-P C R)$}

HeLa cells were incubated with blank NPs, curcumin, and curcumin-loaded CS-ALG-STPP NPs $(50 \mu \mathrm{g} / \mathrm{mL})$ for 48 hours. Then, they were washed with PBS, and RNA was extracted using total RNA extraction kit (Yekta Tajhiz, Tehran, Iran) according to the manufacturer's protocol. cDNA synthesis was performed by a commercially available reverse transcriptase kit (Yekta Tajhiz). A total $20 \mu \mathrm{L}$ of reaction mixture contained $0.4 \mu \mathrm{L}$ forward primer, $0.4 \mu \mathrm{L}$ reverse primer, $2 \mu \mathrm{L}$ cDNA, $10 \mu \mathrm{L}$ SYBR Green PCR master mix (Yekta Tajhiz), $0.4 \mu \mathrm{L}$ carboxy-X-rhodamine (Yekta Tajhiz), and 6.8 $\mu \mathrm{L}$ RNase-free water. GAPDH was used as an internal control. Gene expression level was analyzed by $\mathrm{Ct}$ method. Table $\mathrm{S} 1$ shows the primer sequences and their annealing temperature.

\section{Statistical analysis}

MTT assay data were analyzed using unpaired Student's $t$-test. The qRT-PCR results were analyzed by using one-way 
analysis of variance, followed by Tukey's post hoc test. The results are expressed as mean \pm standard error of mean, and $p$-values $\leq 0.05$ were considered statistically significant.

\section{Results}

\section{Curcumin-loaded CS-ALG-STPP NP}

\section{properties}

FE-SEM results showed that curcumin-loaded CS-ALG-STPP NPs were spherical, with a mean size of $\sim 50 \mathrm{~nm}$, which are agglomerated together (Figure 1A). Figure 1B displays an
AFM image and its three-dimensional view. Consistent with FE-SEM data, the quantification of AFM results also indicated that particles have uniform size distribution, and the average size of curcumin-loaded NPs was $50 \mathrm{~nm}$ (Figure 1C).

\section{FT-IR spectroscopy analysis}

Figure 2 shows the FT-IR spectra of curcumin, CS-ALGSTPP, and curcumin-loaded CS-ALG-STPP NPs. In the spectrum of CS-ALG-STPP NPs, the broad band at $3,432 \mathrm{~cm}^{-1}$ corresponds to hydroxyl and amine groups.

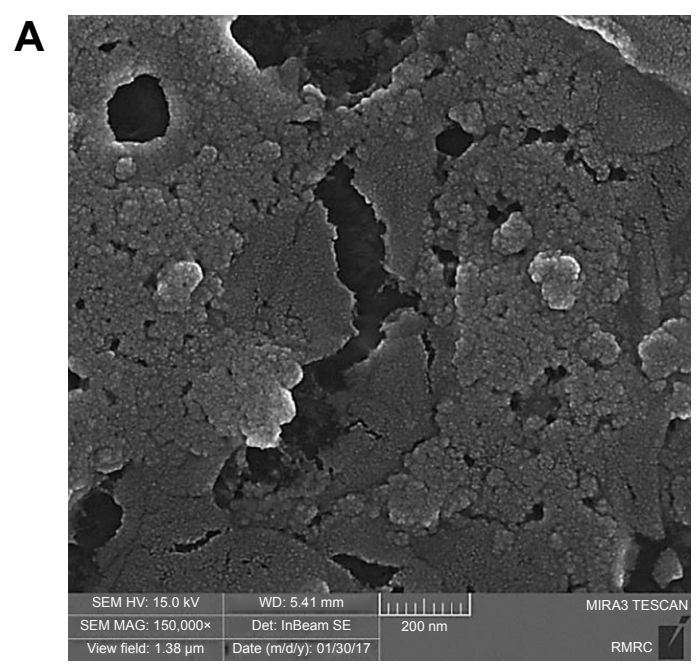

B Topography-scan forward
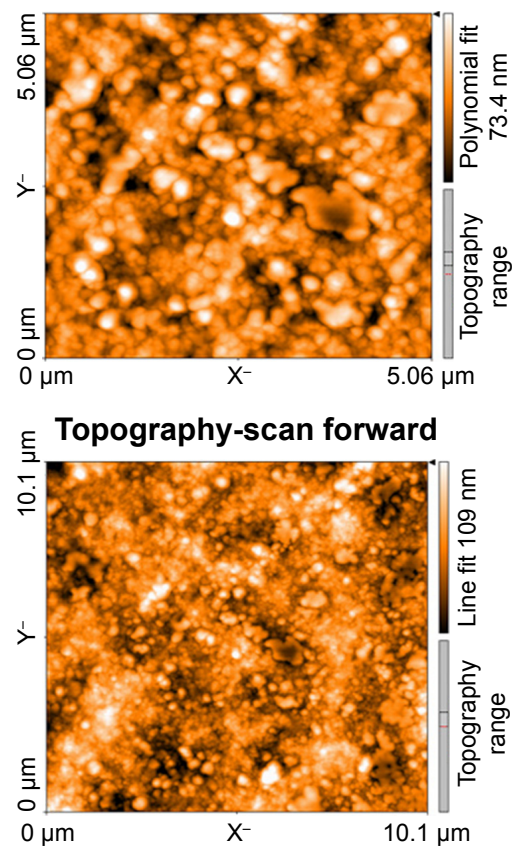

Topography-scan forward

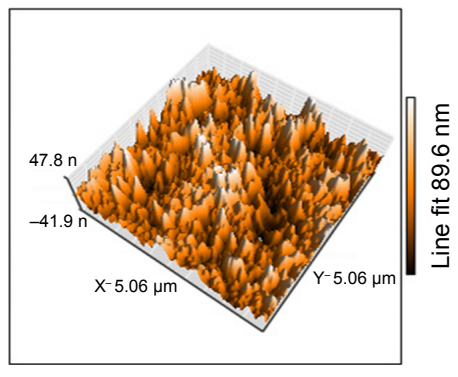

Topography-scan forward

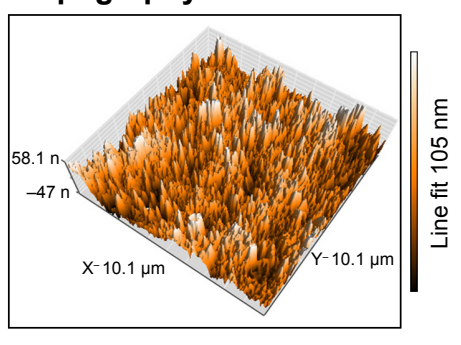

C

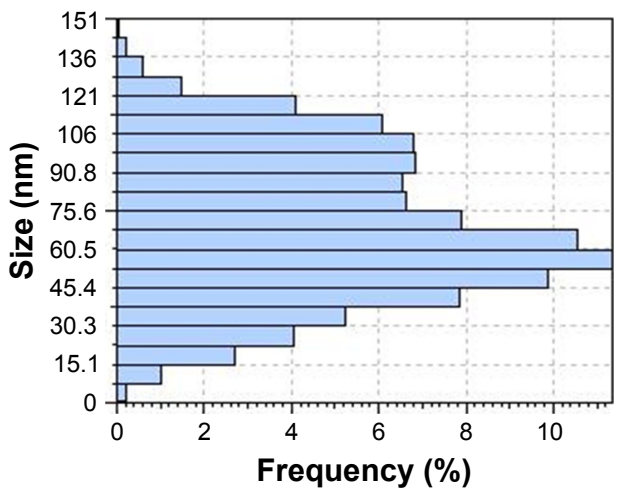

Figure I Curcumin-loaded CS-ALG-STPP NPs characterization.

Notes: (A) FE-SEM data (magnification: I50,000x). (B) Two and three dimensional images of AFM result. (C) Quantification of AFM data indicated that curcumin-loaded NPs had spherical shape with an average size of $50 \mathrm{~nm}$.

Abbreviations: AFM, atomic force microscopy; CS-ALG-STPP NPs, chitosan-alginate-sodium tripolyphosphate nanoparticles; FE-SEM, field emission scanning electron microscopy. 


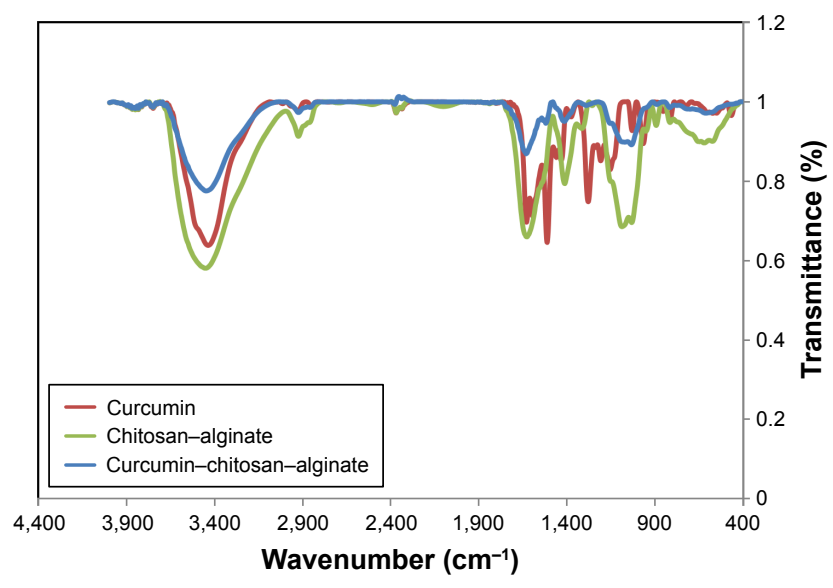

Figure 2 FT-IR spectra of curcumin, CS-ALG, and curcumin-loaded CS-ALG-STPP. Abbreviations: CS-ALG-STPP, chitosan-alginate-sodium tripolyphosphate; FT-IR, Fourier transform infrared.

The peaks near 1,630 and $1,413 \mathrm{~cm}^{-1}$ are attributed to the symmetric and asymmetric stretching vibrations of $\mathrm{COO}^{-}$ groups, respectively. Moreover, the band around $1,026 \mathrm{~cm}^{-1}$ belongs to the amide bands. The peak at $1,087 \mathrm{~cm}^{-1}$ is due to the presence of $-\mathrm{CH}-\mathrm{OH}$ in cyclic alcohol and $\mathrm{C}-\mathrm{O}$ stretch. For curcumin, the peak at $3,478 \mathrm{~cm}^{-1}$ corresponds to amine groups. The adsorption peak at $1,510 \mathrm{~cm}^{-1}$ is observed, which corresponds to the $\mathrm{C}=\mathrm{O}$ and $\mathrm{C}=\mathrm{C}$ vibrations of curcumin.
In addition, an absorption peak for $\mathrm{C}=\mathrm{C}$ double bands at $1,627 \mathrm{~cm}^{-1}$ is not clear in this spectrum because of its overlapping with CS-ALG-STPP peak. The relative peak intensities of curcumin-loaded CS-ALG-STPP NPs are slightly weak, which may be due to the attachment of curcumin on functional groups of CS-ALG matrix.

\section{Entrapment efficiency}

In order to assess the encapsulation efficiency, HPLC analysis was performed on decanted solution, solution after washing with ethanol, and curcumin-loaded CS-ALG-STPP NPs mixture in water. By calculating the area under the peaks, the entrapment efficiency for NP preparation was about $70 \%$ (Figure 3).

\section{In vitro release of curcumin from CS-ALG-STPP NPs}

The in vitro drug release profile was evaluated at a predetermined time, and the percentage of curcumin released from CS-ALG-STPP NPs was measured by using a standard curve. Figure 4 shows the in vitro drug release profile of curcumin-loaded NPs. Our data indicated that 24\% and 29\% of curcumin were released from NPs after 1 and 2 hours,

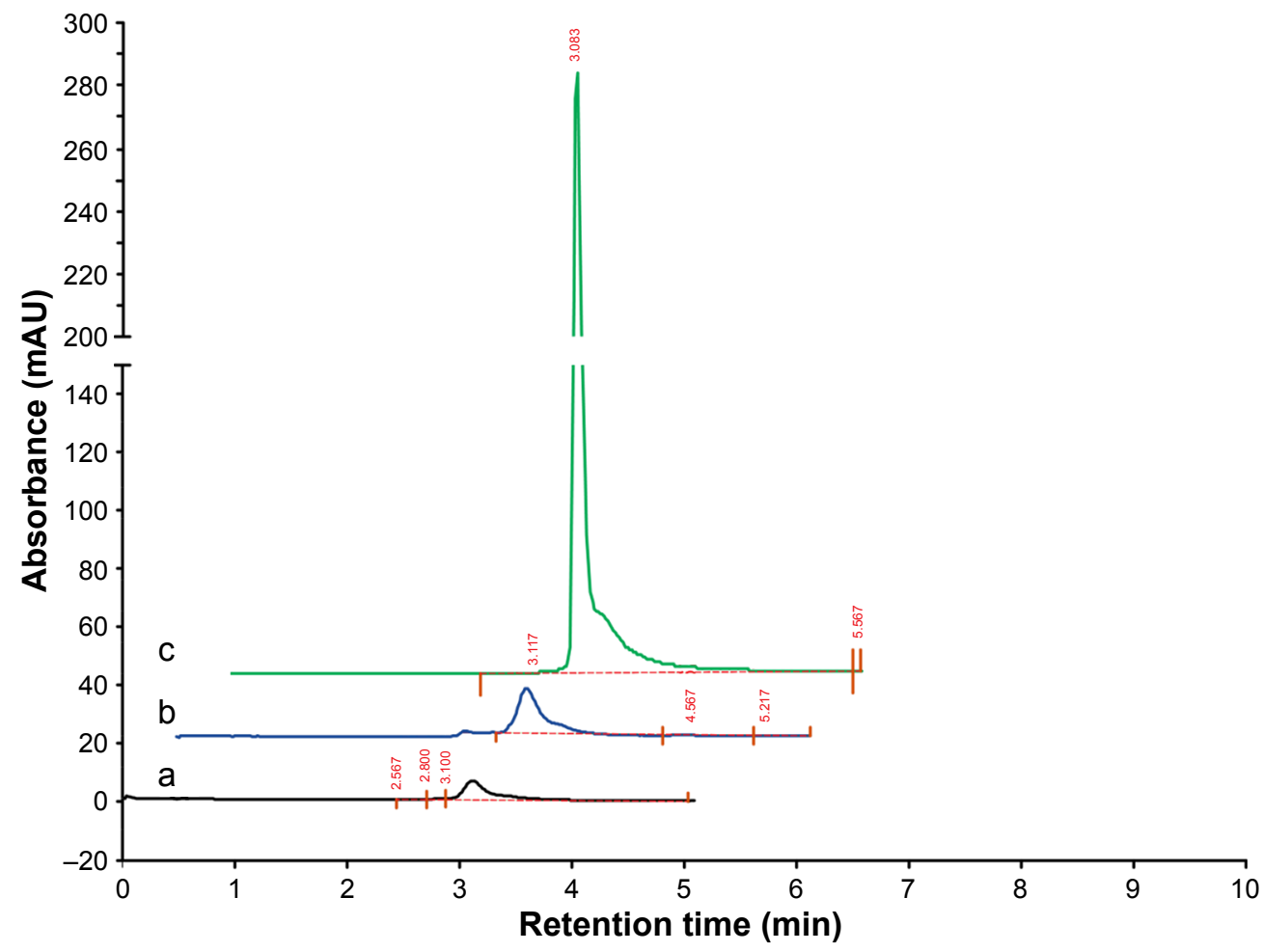

Figure 3 Entrapment efficiency.

Notes: HPLC analysis for (a) decanted solution, (b) solution after washing with ethanol, and (c) curcumin-loaded CS-ALG-STPP NPs in aqueous solution. Abbreviations: CS-ALG-STPP NPs, chitosan-alginate-sodium tripolyphosphate nanoparticles; HPLC, high-performance liquid chromatography. 


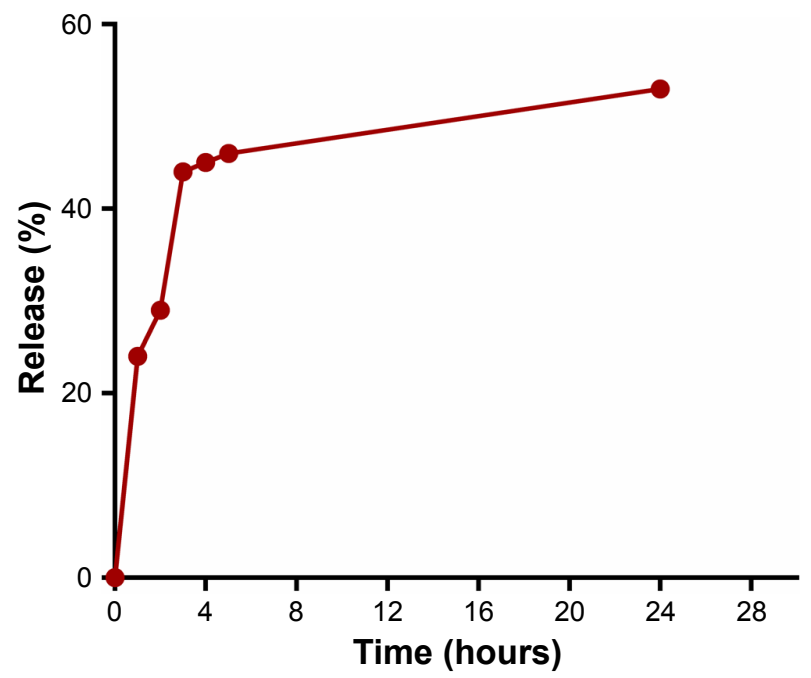

Figure $\mathbf{4}$ In vitro release kinetics of curcumin-loaded CS-ALG-STPP NPs. Abbreviation: CS-ALG-STPP NPs, chitosan-alginate-sodium tripolyphosphate nanoparticle.

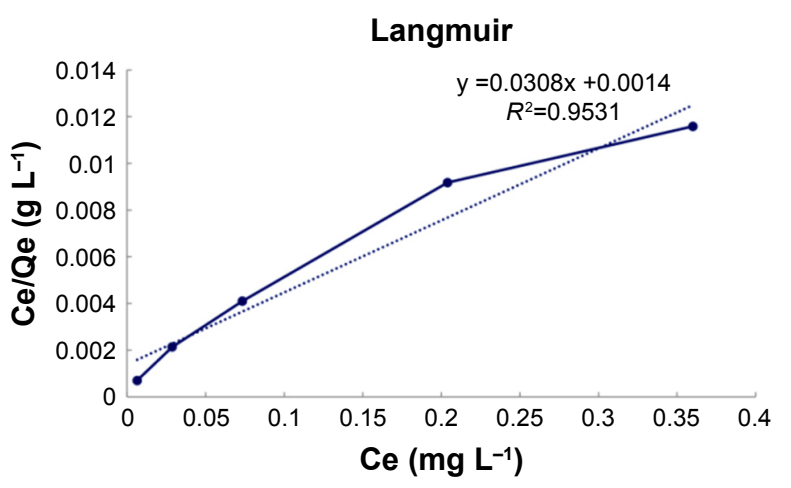

Fruendlich

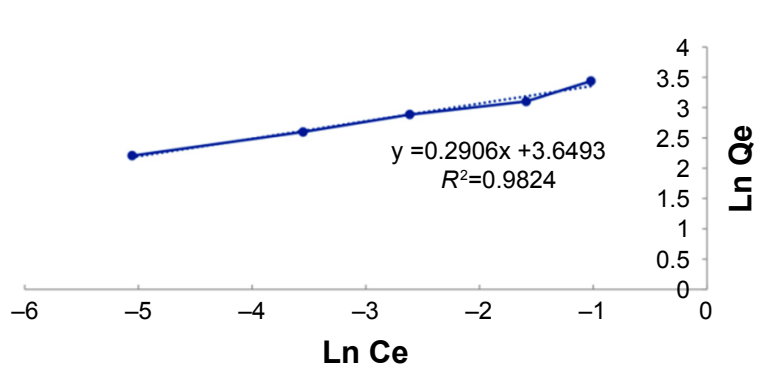

respectively. Then, a highly controlled release was observed till 24 hours, and 53\% of physically loaded curcumin was released during this period (Figure 4).

\section{Adsorption affinity of curcumin and CS-ALG-STPP NPs}

Isotherm process was carried out to assess the curcumin loading capacity onto CS-ALG-STPP NPs. Figure 5 depicts the adsorption isotherms for curcumin and CS-ALG-STPP NPs. Experimental results were fit to Langmuir, Freundlich, Temkin, Elovich, and Langmuir-Freundlich isotherm equations. Table 1 presents the adsorption isotherm data for curcumin on CS-ALG-STPP NPs and the equilibrium parameters. Regression analysis showed that among the mentioned isotherms, Langmuir-Freundlich isotherm model exhibits the highest linearity $\left(R^{2}=992\right)$.

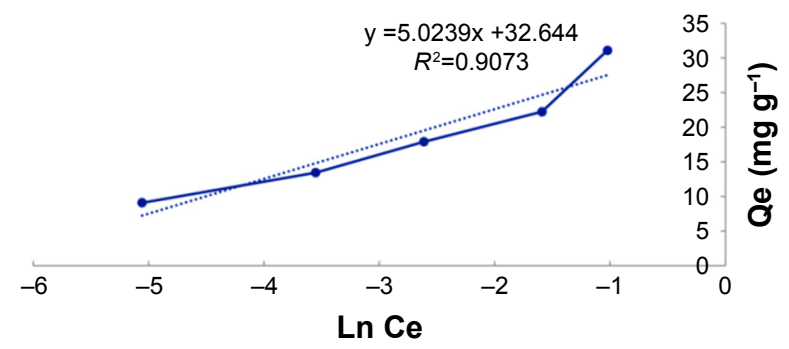

Elovich

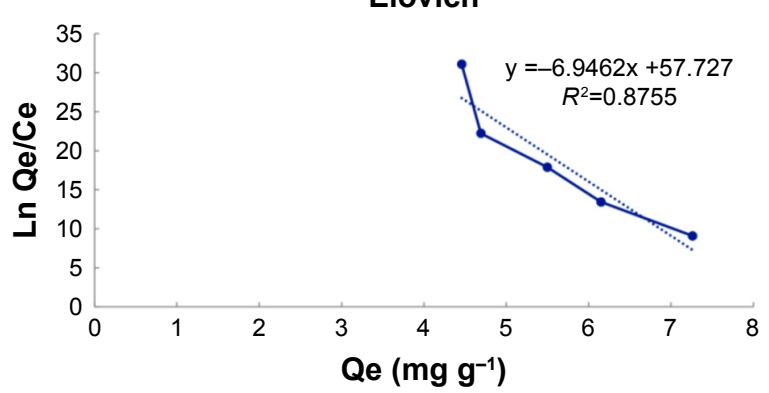

Langmuir-Fruendlich

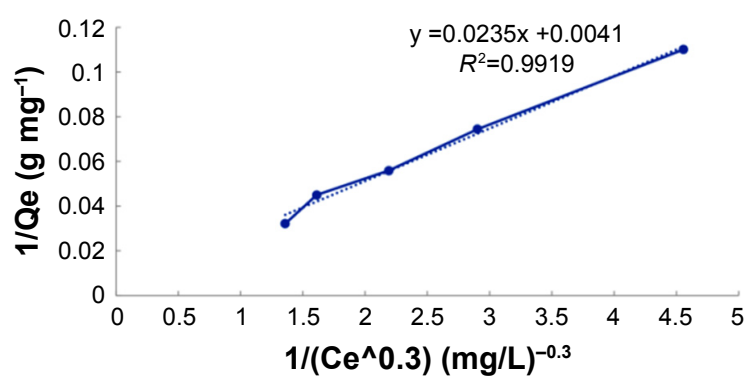

Figure 5 Adsorption isotherms of curcumin-loaded CS-ALG-STPP nanoparticles. Adsorption of curcumin onto CS-ALG-STPP NPs has been evaluated with different isotherm models, and regression analysis indicated that high linearity will be obtained using Langmuir-Freundlich isotherm model fit.

Abbreviation: CS-ALG-STPP NPs, chitosan-alginate-sodium tripolyphosphate nanoparticles. 
Table I Isotherm constants for adsorption of curcumin onto CS-ALG-STPP NPs

\begin{tabular}{lll}
\hline Model & Parameters & Values \\
\hline Langmuir isotherm & $\mathrm{q}_{\mathrm{m}}\left(\mathrm{mg} \mathrm{g}^{-1}\right)$ & 32.467 \\
& $\mathrm{~K}_{\mathrm{L}}(\mathrm{L} \mathrm{mg})$ & 22.000 \\
& $\mathrm{R}^{2}$ & 0.953 \\
\hline Freundlich isotherm & $\mathrm{n}$ & $3.44 \mathrm{I}$ \\
& $\mathrm{K}_{\mathrm{F}}\left(\mathrm{mg}^{1-(1 / \mathrm{n})} \mathrm{L}^{1 / \mathrm{n}} \mathrm{g}^{-1}\right)$ & 38.448 \\
& $\mathrm{R}^{2}$ & 0.982 \\
\hline Temkin isotherm & $\mathrm{B}_{\mathrm{T}}\left(\mathrm{mol}^{-1}\right)$ & 5.024 \\
& $\mathrm{~K}_{\mathrm{T}}\left(\mathrm{L} \mathrm{g}^{-1}\right)$ & 663.555 \\
& $\mathrm{R}^{2}$ & 0.907 \\
\hline Elovich isotherm & $\mathrm{q}_{\mathrm{m}}\left(\mathrm{mg} \mathrm{g}^{-1}\right)$ & 0.144 \\
& $\mathrm{~K}_{\mathrm{E}}\left(\mathrm{L} \mathrm{g} \mathrm{g}^{-1}\right)$ & $8.169 * 1025$ \\
& $\mathrm{R}^{2}$ & 0.875 \\
\hline Langmuir-Freundlich & $\mathrm{q}_{\mathrm{m}}\left(\mathrm{mg} \mathrm{g}^{-1}\right)$ & 243.902 \\
& $\mathrm{~K}_{\mathrm{c}}$ & 0.174 \\
& $\mathrm{n}$ & 3.333 \\
& $\mathrm{R}^{2}$ & 0.992
\end{tabular}

Abbreviations: CS-ALG-STPP NPs, chitosan-alginate-sodium tripolyphosphate nanoparticles; $\mathrm{q}_{\mathrm{m}}$, maximum curcumin uptake.

The maximum curcumin uptake $\left(\mathrm{q}_{\mathrm{m}}\right)$ was obtained; $243.902 \mathrm{mg}$ of curcumin was adsorbed per gram of CS-ALGSTPP NPs. According to this model, intermolecular interactions have an important role in the adsorption of curcumin onto CS-ALG-STPP NPs.

\section{In vitro assays}

Based on the intrinsic fluorescence activity of curcumin, its uptake was evaluated in HeLa cells, 48 hours after curcumin-loaded CS-ALG-STPP NP incubation. Florescence microscopic images indicated that control cells and those incubated with CS-ALG-STPP NPs as blank NPs experimental group did not show any fluorescence activity. In contrast to control and blank NPs (carrier) experimental groups, HeLa cells treated with free curcumin or curcumin NPs $(50 \mu \mathrm{g} / \mathrm{mL})$ robustly exhibited green fluorescence (Figure 6A). In the next step, the cytotoxic effect of curcumin-loaded NPs was assessed by using MTT assay. Human foreskin fibroblasts and HeLa cells were incubated by different doses of free curcumin or curcumin-loaded CS-ALG-STPP NPs (6.25, $12.5,25,50$, and $100 \mu \mathrm{g} / \mathrm{mL}$ ) for 48 hours. To evaluate the toxicity of the curcumin NPs on normal cells, human foreskin fibroblasts were cultured and incubated with different concentrations of curcumin or curcumin NPs for 48 hours. The MTT assay results showed that significant cytotoxic effect was not detected in normal cultured cells under the treatment of curcumin or curcumin-loaded NPs (Figure 6B). Furthermore, the cytotoxic effect of curcumin-loaded NPs was assessed in HeLa cancer cell lines. Cell viability assay results showed that curcumin-loaded NPs, especially its high dose, had a significant dose-dependent inhibitory effect on cell proliferation compared with the free curcumin group (Figure 6B).

\section{Effect of curcumin-loaded NPs on apoptosis-related gene expression}

To assess the effect of curcumin-loaded CS-ALG-STPP NPs on apoptosis, HeLa cells were incubated with blank NPs, free curcumin, or curcumin-loaded CS-ALGSTPP NPs $(50 \mu \mathrm{g} / \mathrm{mL})$ for 48 hours. Nuclear staining was carried out using DAPI, and nucleolus changes were observed under fluorescent microscope. Our data showed that untreated and blank NPs receiving cells were stained equably blue fluorescence. In cells treated with curcumin-loaded CSALG-STPP NPs, DNA fragmentation, nucleolus pyknosis, and bright fluorescence emission, as apoptotic features, were observed. In contrast to curcumin-loaded NPs, curcumin treatment could not induce remarkable changes on nuclear morphology (Figure 7A).

In order to determine the effect of curcumin-loaded CSALG-STPP NPs on apoptotic gene expression, qRT-PCR was performed. qRT-PCR data demonstrated that curcuminloaded CS-ALG-STPP NPs significantly increased the level of Bax gene expression as apoptotic gene marker compared with the carrier and free curcumin groups. Curcuminloaded NPs remarkably decreased the $B c l 2$ gene expression as antiapoptotic gene marker. In addition, the $B c l 2$ gene expression level was also significantly decreased in cells incubated with carrier compared with the free curcumin group (Figure 7B).

\section{Discussion}

Ample evidence has suggested that curcumin exerts a potent anticancer activity on different cancerous cells. ${ }^{39}$ However, because of poor aqueous solubility and low bioavailability, its clinical application has been limited. ${ }^{40}$ Development of novel formulation for the encapsulation of curcumin attracts a strong interest in nanomedicine field. An ideal NP should be stable in the long term, and for circulation in smallest capillary, their size should be $<100 \mathrm{~nm} .{ }^{38}$ In addition, all materials for NP synthesis should be biocompatible..$^{38}$ Another important factor in NP manufacturing is the ability of particles for passing through blood-brain barrier. ${ }^{38}$ As mentioned previously, the size of NPs is an important parameter in successful internalization of particles to cancer cells. ${ }^{38}$ Several studies indicated that particle size in the range of $10-100 \mathrm{~nm}$ is ideal for cancer therapy. ${ }^{41}$ In our study, FE-SEM and AFM data showed that the size of curcumin-loaded CS-ALG-STPP NPs is $<50 \mathrm{~nm}$. A previous study by Das et al showed that 


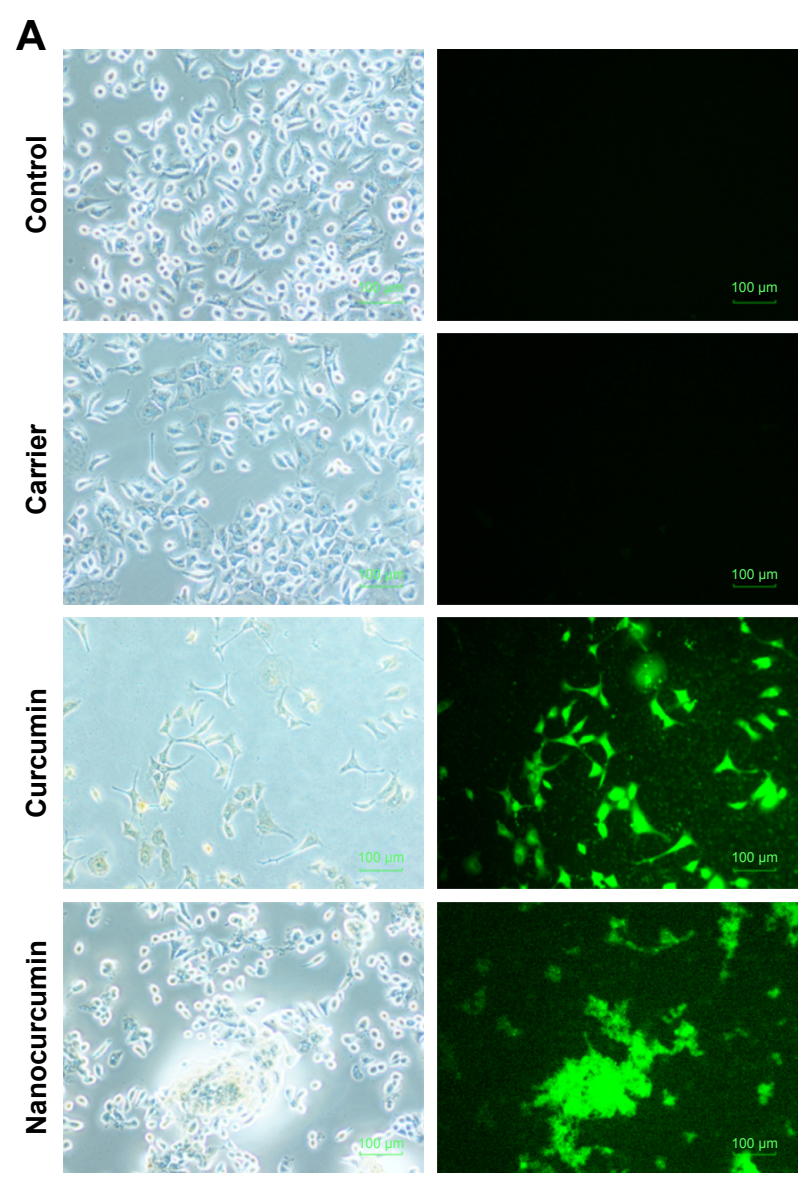

B

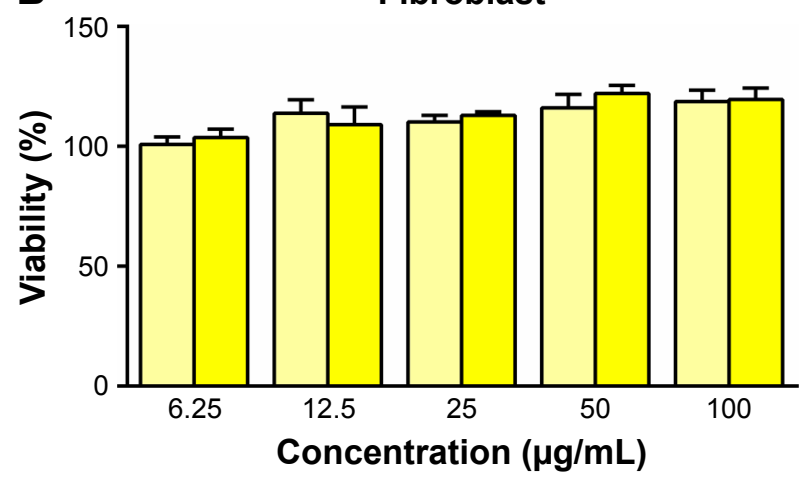

Fibroblast

Free curcumin $\square$ Nanocurcumin

Figure 6 In vitro assays.

Notes: (A) Bright field and fluorescence images of free curcumin and curcumin-loaded nanoparticles $(50 \mu \mathrm{g} / \mathrm{mL})$ uptake by HeLa cells. Scale bar: $100 \mu \mathrm{m}$; magnification $100 \times$. (B) MTT results showed that curcumin-loaded nanoparticles have suppressed the proliferation of HeLa cells in a dose-dependent manner compared with free curcumin. $*_{p}<0.05$ and $* * * p<0.001, \mathrm{n}=3$

Abbreviation: HeLa, human cervical epithelioid carcinoma.

curcumin-loaded NPs could be synthesized by applying ALG as the cross-linker into CS solution, and the size of the prepared particles was $100 \mathrm{~nm} .^{32}$ Another study showed that the size of curcumin-loaded CS NPs was $>200 \mathrm{~nm}^{42}$ In addition, Mirnejad et al used CS and TPP for curcumin loading, and particle size was $160 \mathrm{~nm} \cdot{ }^{29}$ In contrast to the mentioned studies, we could prepare curcumin-loaded NPs with smaller size. Probably, applying different concentrations of CS, ALG, and STPP and subsequent ultrasonication of final solution can result in the synthesis of NPs with desirable size in cancer therapeutic approach. In agreement with previous reports, ${ }^{29,32}$ our in vitro drug release results also 
A
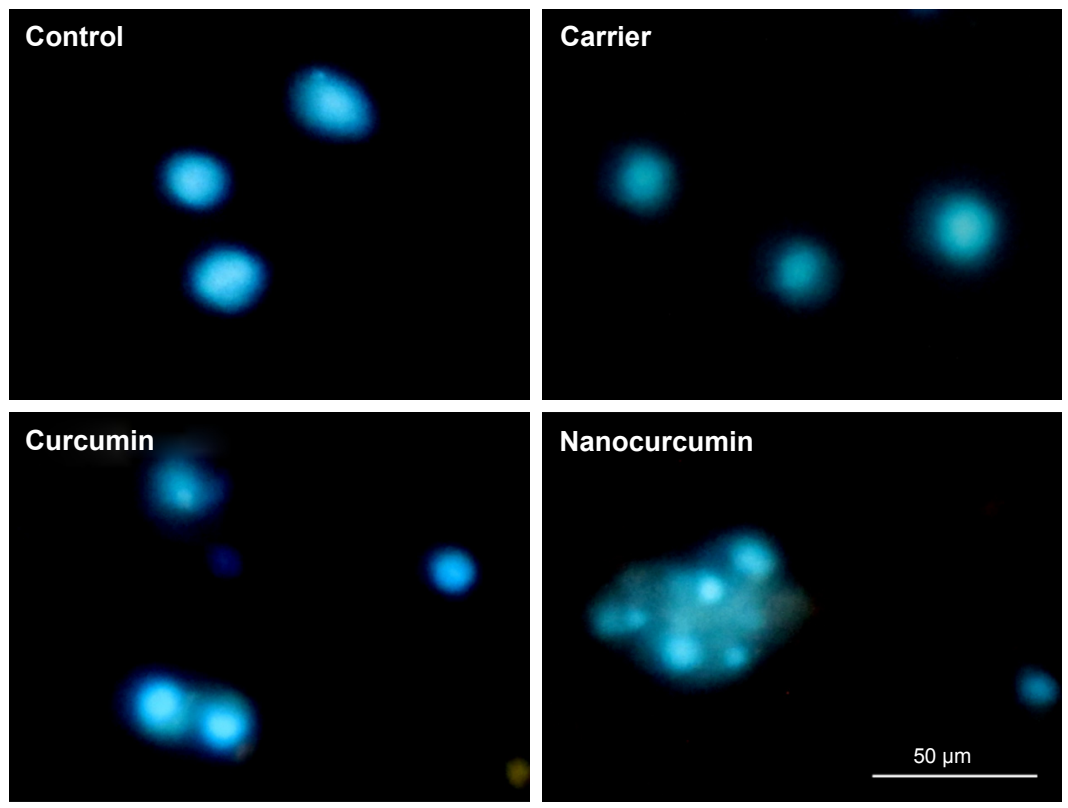

B

Bax

$B c / 2$
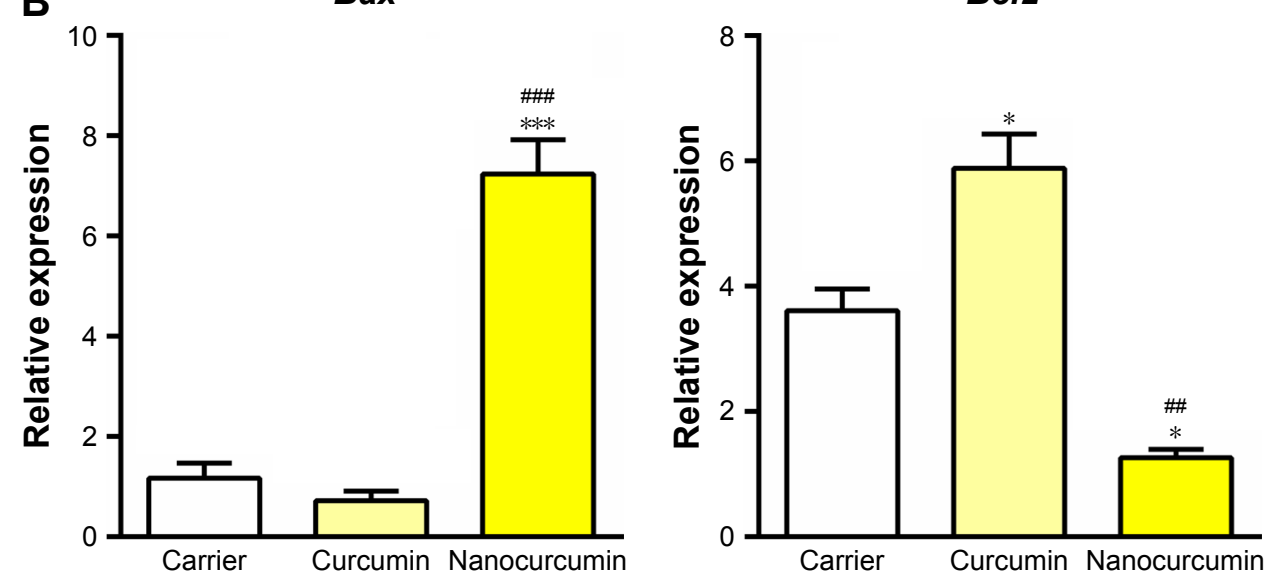

Figure 7 Effect of curcumin-loaded nanoparticles on cell apoptosis.

Notes: (A) Nuclear staining using DAPI showed that nucleolus morphological changes have been occurred in cells under the treatment of curcumin-loaded CS-ALG-STPP nanoparticles. Scale bar: $50 \mu \mathrm{m}$; magnification $200 \times$ (B) qRT-PCR data indicated that curcumin-loaded CS-ALG-STPP NPs significantly increased the apoptotic gene expression $(\mathrm{Bax})$ and decreased the antiapoptotic gene expression $(\mathrm{Bc} / 2)$ compared with carrier and free curcumin experimental groups. ${ }^{*} p<0.05$ and $*_{*} * p<0.00 \mathrm{I}$ nanocurcumin compared with carrier group; ${ }^{\#} p \leq 0.01$ and ${ }^{\#} p \leq 0.00$ I curcumin nanoparticles compared with free curcumin.

Abbreviations: CS-ALG-STPP NPs, chitosan-alginate-sodium tripolyphosphate nanoparticles; qRT-PCR, quantitative real-time polymerase chain reaction.

showed 53\% release of curcumin from NPs within 24 hours. Because of the nature of CS and its better solubility in acidic $\mathrm{pH}$, the slower release of curcumin is occurred at a $\mathrm{pH}$ of 7.4. ${ }^{29}$ The initial burst release is perhaps due to the attachment of curcumin on the surface of NPs. ${ }^{43}$ After the initial burst, a sustained release was observed for curcumin-loaded NPs. The controlled release of drugs from NPs is considered as an essential factor in drug delivery approach. ${ }^{43}$

The encapsulation efficiency for curcumin-loaded CS-ALG-STPP NPs was obtained, which was about $70 \%$. Mirnejad et al also showed that the encapsulation efficiency of curcumin-loaded CS-TPP NPs was 75\%. ${ }^{29}$ However,
Das et al showed that the entrapment efficiency of curcuminloaded CS-ALG NPs is $<20 \% .{ }^{32}$ However, in the present study, we achieved a higher curcumin loading efficiency, which may result from the use of STPP as a cross-linker. Beside the NP size, the binding affinity between curcumin and CS-ALG-STPP NPs is regarded as a critical factor in NP manufacturing. Studying the adsorption process using different isotherm models showed that curcumin preferentially adsorbs to CS-ALG-STPP NPs by intermolecular interaction (Langmuir-Freundlich model). Previous studies have shown that curcumin can be adhered to amine-functionalized mesoporous silica (AAS-MS) NPs using intermolecular 
interaction of curcumin as well as its interaction with NPs. ${ }^{44}$ Due to the hydrophobic structure of curcumin and AAS-MS NPs, hydrophobic attractive forces are regarded as an important reason for intermolecular interactions. ${ }^{44}$ In the next step, the antitumor activity of curcumin-loaded CS-ALG-STPP NPs was investigated. MTT assay and qRT-PCR data suggested that, in contrast to free curcumin, curcumin-loaded NPs effectively inhibit HeLa cell proliferation and induce apoptosis, respectively. Previous reports have suggested that curcumin inhibits cancer cell proliferation and induces cell death, ${ }^{45}$ but in our study, free curcumin could not exert a significant antitumor activity compared with the curcuminloaded NPs. This observation may result from very fine dispersion ability of curcumin-loaded CS-ALG-STPP NPs in aqueous solution and the possibility that this property might have been preserved for several months. Unlike our study, Das et al reported that curcumin-loaded CS-ALG NPs exhibit very poor solubility in aqueous solution, and therefore, pluronic F127 composite was used for enhancing the solubility of these NPs. ${ }^{32}$ The well-dispersion property and also the small size of NPs may lead to better anticancer activity of curcumin-loaded CS-ALG-STPP NPs compared with the free curcumin. Similar to the group received curcumin-loaded CS-ALG-STPP NPs, we have observed that the level of Bcl2 gene expression (as the antiapoptotic factor) has reduced in cells received blank NPs compared with the free curcumin. Previous studies have also demonstrated that CS possesses anticancer activity against several cancer cell lines including oral cancer cells. ${ }^{46}$ It has been shown that the cytotoxic effect of CS is mediated through the induction of apoptosis in oral cancer cells. ${ }^{47}$ Based on such evidence, the significant reduction in $\mathrm{Bcl} 2$ gene expression may result from the anticancer property of CS. However, we did not find any significant difference on Bax gene expression between groups treated by free curcumin or blank NPs.

\section{Conclusion}

In conclusion, curcumin-loaded NPs were successfully prepared by using ultrasonication of biodegradable polymers including CS and ALG. Curcumin-loaded CS-ALG-STPP NPs were homogenously dispersed in aqueous solution, and their ideal size for cancer therapy was obtained. These NPs could be internalized into HeLa cancer cells, and the incubation of HeLa cells with curcumin-loaded CS-ALGSTPP NPs led to suppression of proliferation. In addition, the expression of apoptotic genes was increased in cells treated by curcumin-loaded NPs. These findings may provide a novel therapeutic approach in cancer therapy.

\section{Acknowledgments}

This work was supported by a grant (Number 9503023) from Student Research Committee, Babol University of Medical Sciences, Babol, Mazandaran, Iran. The authors are thankful to Dr Alireza Mani for editing the article.

\section{Disclosure}

The authors report no conflicts of interest in this work.

\section{References}

1. Cao J, Jiang LP, Liu Y, Yang G, Yao XF, Zhong LF. Curcumin-induced genotoxicity and antigenotoxicity in HepG2 cells. Toxicon. 2007; 49(8):1219-1222.

2. Sa G, Das T. Anti cancer effects of curcumin: cycle of life and death. Cell Div. 2008;3(1):14.

3. Salem M, Rohani S, Gillies ER. Curcumin, a promising anti-cancer therapeutic: a review of its chemical properties, bioactivity and approaches to cancer cell delivery. RSC Adv. 2014;4(21):10815-10829.

4. Motterlini R, Foresti R, Bassi R, Green CJ. Curcumin, an antioxidant and anti-inflammatory agent, induces heme oxygenase- 1 and protects endothelial cells against oxidative stress. Free Radic Biol and Med. 2000;28(8):1303-1312.

5. Ringman JM, Frautschy SA, Cole GM, Masterman DL, Cummings JL. A potential role of the curry spice curcumin in Alzheimer's disease. Curr Alzheimer Res. 2005;2(2):131-136.

6. Jurenka JS. Anti-inflammatory properties of curcumin, a major constituent of Curcuma longa: a review of preclinical and clinical research. Altern Med Rev. 2009;14(2);141-153.

7. De R, Kundu P, Swarnakar S, et al. Antimicrobial activity of curcumin against Helicobacter pylori isolates from India and during infections in mice. Antimicrob Agents Chemother. 2009;53(4):1592-1597.

8. Phan TT, See P, Lee ST, Chan SY. Protective effects of curcumin against oxidative damage on skin cells in vitro: its implication for wound healing. J Trauma. 2001;51(5):927-931.

9. Notarbartolo M, Poma P, Perri D, Dusonchet L, Cervello M, D'Alessandro N. Antitumor effects of curcumin, alone or in combination with cisplatin or doxorubicin, on human hepatic cancer cells. Analysis of their possible relationship to changes in NF-kB activation levels and in IAP gene expression. Cancer Lett. 2005;224(1):53-65.

10. Dorai T, Cao YC, Dorai B, Buttyan R, Katz AE. Therapeutic potential of curcumin in human prostate cancer. III. Curcumin inhibits proliferation, induces apoptosis, and inhibits angiogenesis of $\mathrm{LNCaP}$ prostate cancer cells in vivo. Prostate. 2001;47(4):293-303

11. Lin YG, Kunnumakkara AB, Nair A, et al. Curcumin inhibits tumor growth and angiogenesis in ovarian carcinoma by targeting the nuclear factor-אB pathway. Clin Cancer Res. 2007;13(11):3423-3430.

12. Ramachandran $C$, Rodriguez $S$, Ramachandran R, et al. Expression profiles of apoptotic genes induced by curcumin in human breast cancer and mammary epithelial cell lines. Anticancer Res. 2005;25(5): 3293-3302.

13. Kunnumakkara AB, Guha S, Krishnan S, Diagaradjane P, Gelovani J, Aggarwal BB. Curcumin potentiates antitumor activity of gemcitabine in an orthotopic model of pancreatic cancer through suppression of proliferation, angiogenesis, and inhibition of nuclear factor- $\mathrm{\kappa B}-$ regulated gene products. Cancer Res. 2007;67(8):3853-3861.

14. Cai XZ, Wang J, Li XD, et al. Curcumin suppresses proliferation and invasion in human gastric cancer cells by down-regulation of PAK1 activity and cyclin D1 expression. Cancer Biol Ther. 2009;8(14): 1360-1368.

15. Reuter S, Eifes S, Dicato M, Aggarwal BB, Diederich M. Modulation of anti-apoptotic and survival pathways by curcumin as a strategy to induce apoptosis in cancer cells. Biochem Pharmacol. 2008;76(11): 1340-1351. 
16. Liu E, Wu J, Cao W, et al. Curcumin induces G2/M cell cycle arrest in a p53-dependent manner and upregulates ING4 expression in human glioma. J Neuro-oncol. 2007;85(3):263-270.

17. Kim TH, Jiang HH, Youn YS, et al. Preparation and characterization of water-soluble albumin-bound curcumin nanoparticles with improved antitumor activity. Int J Pharm. 2011;403(1):285-291.

18. Shaikh J, Ankola DD, Beniwal V, Singh D, Kumar MR. Nanoparticle encapsulation improves oral bioavailability of curcumin by at least 9-fold when compared to curcumin administered with piperine as absorption enhancer. Eur J Pharm Sci. 2009;37(3):223-230.

19. Narayanan NK, Nargi D, Randolph C, Narayanan BA. Liposome encapsulation of curcumin and resveratrol in combination reduces prostate cancer incidence in PTEN knockout mice. Int J Cancer. 2009; 125(1):1-8.

20. Mollazade M, Nejati-Koshki K, Akbarzadeh A, et al. PAMAM dendrimers augment inhibitory effects of curcumin on cancer cell proliferation: possible inhibition of telomerase. Asian Pac J Cancer Prev. 2013;14(11):6925-6928.

21. Bisht S, Feldmann G, Soni S, et al. Polymeric nanoparticle-encapsulated curcumin ("nanocurcumin"): a novel strategy for human cancer therapy. J Nanobiotechnology. 2007;5(1):3.

22. Mangalathillam S, Rejinold NS, Nair A, Lakshmanan VK, Nair SV, Jayakumar R. Curcumin loaded chitin nanogels for skin cancer treatment via the transdermal route. Nanoscale. 2012;4(1):239-250.

23. Yadav VR, Prasad S, Kannappan R, et al. RETRACTED: Cyclodextrincomplexed curcumin exhibits anti-inflammatory and antiproliferative activities superior to those of curcumin through higher cellular uptake. Biochem Pharmacol. 2010;80(7):1021-1032.

24. Sahu A, Bora U, Kasoju N, Goswami P. Synthesis of novel biodegradable and self-assembling methoxy poly (ethylene glycol)-palmitate nanocarrier for curcumin delivery to cancer cells. Acta Biomater. 2008;4(6): 1752-1761.

25. Li P, Dai YN, Zhang JP, Wang AQ, Wei Q. Chitosan-alginate nanoparticles as a novel drug delivery system for nifedipine. Int J Biomed Sci. 2008;4(3):221-228.

26. De S, Robinson D. Polymer relationships during preparation of chitosan-alginate and poly-l-lysine-alginate nanospheres. J Control Release. 2003;89(1):101-112.

27. Murata Y, Jinno D, Liu D, Isobe T, Kofuji K, Kawashima S. The drug release profile from calcium-induced alginate gel beads coated with an alginate hydrolysate. Molecules. 2007;12(11):2559-2566.

28. Chuah LH, Billa N, Roberts CJ, Burley JC, Manickam S. Curcumincontaining chitosan nanoparticles as a potential mucoadhesive delivery system to the colon. Pharm Dev Technol. 2013;18(3):591-599.

29. Mirnejad R, Jahromi MAM, Al-Musawi S, et al. Curcumin-loaded chitosan tripolyphosphate nanoparticles as a safe, natural and effective antibiotic inhibits the infection of Staphylococcus aureus and Pseudomonas aeruginosa in vivo. Iran J Biotechnol. 2014;12(3):1-8.

30. Siddique YH, Khan W, Singh BR, Naqvi AH. Synthesis of alginatecurcumin nanocomposite and its protective role in transgenic Drosophila model of Parkinson's disease. ISRN Pharmacol. 2013;2013:794582.

31. Saralkar P, Dash AK. Alginate nanoparticles containing curcumin and resveratrol: preparation, characterization, and in vitro evaluation against DU145 prostate cancer cell line. AAPS PharmSciTech. Epub 2017 Apr 10.
32. Das RK, Kasoju N, Bora U. Encapsulation of curcumin in alginatechitosan-pluronic composite nanoparticles for delivery to cancer cells. Nanomedicine. 2010;6(1):153-160.

33. Dai M, Zheng X, Xu X, et al. Chitosan-alginate sponge: preparation and application in curcumin delivery for dermal wound healing in rat. J BioMed Biotechnol. 2009;2009:595126.

34. Karri VV, Kuppusamy G, Talluri SV, et al. Curcumin loaded chitosan nanoparticles impregnated into collagen-alginate scaffolds for diabetic wound healing. Int J Biol Macromol. 2016;93:1519-1529.

35. Suryani, Halid NHA, Akib NI, Rahmanpiu, Mutmainnah N. Preparation of curcumin nanoparticle by using reinforcement ionic gelation technique. Paper presented at: AIP Conference Proceedings; 2017;1838(1).

36. Caetano LA, Almeida AJ, Gonçalves LM. Effect of experimental parameters on alginate/chitosan microparticles for BCG encapsulation. Mar Drugs. 2016;14(5):pii: E 90.

37. Liu J, Xu L, Liu C, et al. Preparation and characterization of cationic curcumin nanoparticles for improvement of cellular uptake. Carbohydr Polym. 2012;90(1):16-22.

38. Cheng KK, Chan PS, Fan S, et al. Curcumin-conjugated magnetic nanoparticles for detecting amyloid plaques in Alzheimer's disease mice using magnetic resonance imaging (MRI). Biomaterials. 2015;44: $155-172$.

39. Ravindran J, Prasad S, Aggarwal BB. Curcumin and cancer cells: how many ways can curry kill tumor cells selectively? AAPS J. 2009;11(3): 495-510.

40. Dey S, Sreenivasan K. Conjugation of curcumin onto alginate enhances aqueous solubility and stability of curcumin. Carbohy Polym. 2014; 99:499-507.

41. Portney NG, Ozkan M. Nano-oncology: drug delivery, imaging, and sensing. Anal Bioanal Chem. 2006;384(3):620-630.

42. Akhtar F, Rizvi MM, Kar SK. Oral delivery of curcumin bound to chitosan nanoparticles cured Plasmodium yoelii infected mice. Biotechnol Adv. 2012;30(1):310-320.

43. Rejinold NS, Muthunarayanan M, Chennazhi KP, Nair SV, Jayakumar R. Curcumin loaded fibrinogen nanoparticles for cancer drug delivery. J Biomed Nanotechnol. 2011;7(4):521-534.

44. Taebnia N, Morshedi D, Yaghmaei S, Aliakbari F, Rahimi F, Arpanaei A. Curcumin-loaded amine-functionalized mesoporous silica nanoparticles inhibit $\alpha$-synuclein fibrillation and reduce its cytotoxicity-associated effects. Langmuir. 2016;32(50):13394-13402.

45. Choudhuri T, Pal S, Agwarwal ML, Das T, Sa G. Curcumin induces apoptosis in human breast cancer cells through p53-dependent Bax induction. FEBS Lett. 2002;512(1-3):334-340.

46. Azuma K, Osaki T, Minami S, Okamoto Y. Anticancer and antiinflammatory properties of chitin and chitosan oligosaccharides. JFunct Biomater. 2015;6(1):33-49.

47. Wimardhani YS, Suniarti DF, Freisleben HJ, Wanandi SI, Siregar NC, Ikeda MA. Chitosan exerts anticancer activity through induction of apoptosis and cell cycle arrest in oral cancer cells. J Oral Sci. 2014;56(2): $119-126$. 


\section{Supplementary material}

Table SI Primer sequences

\begin{tabular}{llll}
\hline $\begin{array}{l}\text { Primer } \\
\text { name }\end{array}$ & Sequence $\left(\mathbf{5}^{\prime} \rightarrow \mathbf{3}^{\prime}\right)$ & $\begin{array}{l}\text { Size } \\
(\mathbf{b p})\end{array}$ & $\begin{array}{l}\text { Annealing } \\
\text { temperature } \\
\left({ }^{\circ} \mathbf{C}\right)\end{array}$ \\
\hline GAPDH & $\begin{array}{l}\text { Forward: GGTGGTCTCCTCTGAC } \\
\text { TTCAACA; reverse: }\end{array}$ & 126 & 60 \\
& $\begin{array}{l}\text { GTTGCTGTAGCAAATTCGTTGT } \\
\text { Bax }\end{array}$ & & \\
& $\begin{array}{l}\text { Forward: TGG CAG CTG ACA } \\
\text { TGT TTT CTG AC; reverse: TCA }\end{array}$ & 195 & 60 \\
& $\begin{array}{l}\text { CCC AAC CAC CCT GGT CTT } \\
\text { BCI2 }\end{array}$ & & \\
& $\begin{array}{l}\text { Forward: TCG CCC TGT GGATGA } \\
\text { CTG A; reverse: CAGAGA CAG }\end{array}$ & 60 \\
& CCA GGA GAA ATC A & & \\
\hline
\end{tabular}

\section{Publish your work in this journal}

The International Journal of Nanomedicine is an international, peerreviewed journal focusing on the application of nanotechnology in diagnostics, therapeutics, and drug delivery systems throughout the biomedical field. This journal is indexed on PubMed Central, MedLine, CAS, SciSearch ${ }^{\circledR}$, Current Contents ${ }^{\circledR} /$ Clinical Medicine,

Journal Citation Reports/Science Edition, EMBase, Scopus and the Elsevier Bibliographic databases. The manuscript management system is completely online and includes a very quick and fair peer-review system, which is all easy to use. Visit http://www.dovepress.com/ testimonials.php to read real quotes from published authors.

Submit your manuscript here: http://www.dovepress.com/international-journal-of-nanomedicine-journal 